American Journal of Pharmacology and Toxicology 5 (2): 95-102, 2010

ISSN 1557-4962

(C) 2010 Science Publications

\title{
Antibacterial Activity of Marine Source Extracts Against Multidrug Resistance Organisms
}

\author{
${ }^{1,2}$ Nagi A. AL-Haj, ${ }^{2}$ Nurmas I. Mashan, ${ }^{2,3}$ Mariana N. Shamsudin, \\ ${ }^{4}$ Habsah Mohamad, ${ }^{5}$ Charles S. Vairappan and ${ }^{2}$ Zamberi Sekawi \\ ${ }^{1}$ Department of Medical Microbiology, Faculty of Medicine and Health Sciences, \\ Sana'a University, P.O. Box 13078, Sana'a, Yemen \\ ${ }^{2}$ Department of Microbiology and Parasitology, Faculty of Medicine and Health Sciences, \\ ${ }^{3}$ Department Marine Science and Aquaculture, Institute of Bioscience, \\ University Putra Malaysia, 43400 Serdang, Selangor, Malaysia \\ ${ }^{4}$ Department of Chemical Sciences, Faculty of Science and Technology, \\ University Malaysia Terengganu, 21030 Kuala Terengganu, Terengganu, Malaysia \\ ${ }^{5}$ Laboratory of Natural Products, Department of Chemistry, \\ Institute for Tropical Biology and Conservation, University Malaysia Sabah, \\ 88999 Kota Kinabalu, Sabah, Malaysia
}

\begin{abstract}
Problem statement: Antimicrobial resistance is the major problem of global dimensions with a significant impact on morbidity, mortality and healthcare-associated costs. The problem has recently been worsened by the steady increase in multiresistant strains and by the restriction of antibiotic discovery and development programs. Methicillin-resistant Staphylococcus aureus, pseudomonads and Escherichia coli are a major nosocomial and community-acquired pathogens for which few existing antibiotics are efficacious. The current study was conducted to investigate antibacterial activity of natural seaweed sources. Approach: Gracilaria changii Euchema denticulatum and sea cucumbers extracts against Methicillin-resistant Staphylococcus aureus, Escherichia coli, Streptococcus pyogenes, Vibrio cholerae, Pseudomonas aeruginosa and Klebsiella pneumoniae. Results: The Minimal Inhibitory Concentration (MIC) values and Minimal Bactericidal Concentration (MBC) values of methanol extract were used against all assayed bacteria. Results indicated that $G$. changii, E. denticulatum and sea cucumbers extracts must possess major antibacterial components against infectious microorganisms. Conclusion: The results obtained indicate that Gracilaria changii and Euchema denticulatum could be a source of natural products with antibiotic modifying activity to be used against multidrug resistant bacteria.
\end{abstract}

Key words: Methicillin Resistant Staphylococcus Aureus (MRSA), Extended Spectrum Beta Lactamase (ESBL), Vancomycin Resistant Enterococci (VRE), Multiple Minimal Inhibitory Concentration (MIC) and Minimal Bactericidal Concentration (MBC), Community Acquired Pathogens (CAP)

\section{INTRODUCTION}

Even control continuous use of antibiotics has resulted in multi-resistant bacterial strains all over the world and as expected, hospitals have become breeding grounds for human-associated micro organisms (Mainous and Pomeroy, 2001). There is an urgent need to search for alternatives to synthetic antibiotics. The revaluation of the discovery of new groups of antimicrobial peptides make natural antibiotics the basic element of a novel generation of drugs for the treatment of bacterial and fungal infections (De Lucca, 2000; Hancock, 2000; Selitrennikoff, 2001; Welling et al., 2000). Even some of the wide spectrum of antimicrobial activities it has a potential benefit in the treatment of cancer (Tanaka, 2001) and viral (Andersen et al., 2001; Chernysh et al., 2002; Chinchar et al., 2001). These features make the antibiotic of natural product resources as a powerful arsenal of molecules that could be the antimicrobial

Corresponding Author: Nagi A. AL-Haj, Department of Medical Microbiology, Faculty of Medicine and Health Sciences, Sana'a University, P.O. Box 13078, Sana'a, Yemen Tel: 00967-773579777 
drugs of the new century as an innovative response to the increasing problem of MDR. Anti Microbial Peptides (AMPs) known as new generation native peptide molecules isolated froma full range of organisms and species from bacteria to man, seem to fit this description. As a consequence, they have been termed "natural antibiotics", because they are active against a large spectrum of microorganisms, including bacteria and filamentous fungi-in addition to protozoan and metazoan parasites (Liu et al., 2000). A large group of low molecular weight natural compounds that exhibit antimicrobial activity has been isolated from animals and plants during the past two decades. The evolution of antibiotic-resistant pathogenic bacteria has stimulated the search for alternative antimicrobial agents from alternative sources including sources from the ocean. The powers of marine organisms have been realized for thousands of years and its potential as producers of pharmaceutical products have been reviewed (Baker, 2004). Red algae that are used in this study are Gracilaria changii, which grow mild in Pantai Morib, Selangor and Euchema denticulatum which grow mild and cultivated in Pantai Sabah. Sea cucumber or Holothurian belongs to phylum of echinodermata. Cured products termed beche-de-mer (meaning seaworm), trepang (meaning sea slug) and in Chinese it is called hoi-sum. Sea cucumbers are believed to have some aphrodisiac qualities as well as curing effects on variety of elements. According to Ridzwan et al. (1995) the current research focus on sea cucumber in Malaysia are based on studies which include identification of species, their distributions, nutrition evolution, kinetic properties of crude lactate dehydrogenase and medicinal value. In microbiology term, antibacterial agent is defined as any compound that is clinically useful in the treatment of bacterial infections which may derive from a natural source, synthetic or produced semi synthetically. The increasing prevalence of multi-drug resistant organisms with few or no treatment options such as Methicillin Resistant Staphylococcus Aureus (MRSA), Vancomycin Resistant Enterococci (VRE) and the Extended Spectrum Beta-Lactamase (ESBL) producing gram-negative bacilli both in hospitalized patients and to a lesser extent, in the community are a serious cause for concern and have become a global problem. A member of the Staphylococci group, the S. aureus is perhaps the pathogen of the greatest concern because of its intrinsic virulence, its ability to cause a diverse array of life threatening infections and its capacity to adapt to different environmental conditions (Lowy, 1998). Although it is a part of our natural microflora, however, some strains of $S$. aureus are capable of producing a highly heat-stable toxin that is the main cause of illness in humans (Washington et al., 2006). It can multiply in food held at room temperature and produced the enterotoxins which is resistant to heat, refrigeration and freezing (Schlievert, 1993) causing gastroenteritis or inflammation of the lining of the intestinal tract. It is also released pyrogenic exotoxins into the blood stream and causing toxic shock syndrome. S. aureus grows to higher numbers in pimples, sores and when a person is down with a cold and can causes variety of suppurative (pus forming) infections such as boils and furuncles and deep-seated infections such as osteomyelitis and endocarditis pneumonia. Other infections are mastitis, phlebitis, meningitis and urinary tract infections. This study is in search for the antibacterial properties of natural product such as red algae and Sea cucumber in order to find a new antibacterial agent and peptide that can inhibit or reduce the growth of bacteria in human body. In the present study is designed based on the bioassay and molecular assay for determining antibacterial activity of $G$. changii and E. denticulatum extracts and peptide gene of Sea cucumber respectively. The investigation could scientifically proof the natural products to be potentially potent antibacterial agents.

\section{MATERIALS AND METHODS}

Bacteria sources: Bacteria used in this study, $S$. aureus, Streptococcus pyogenes, E. coli, K. pneumoniae and $P$. aeruginosa were obtained from several hospitals in Malaysia. All of the isolates were provided in the form of pure bacterial stock culture. Bacterial isolates were maintained at $-20^{\circ} \mathrm{C}$ in Luria Bertani broth (Invitrogen Inc.) containing $15 \%$ ( $\mathrm{vol} / \mathrm{vol})$ glycerol.

Sea cucumber sources: Live specimens of sea cucumber (5 species) and tunicate (1 species) were collected from Beting Darat, Gelang Patah, Johore. For genomic extraction, samples were cut in to small pieces and preserved in TNEAS buffer.

Genomic extraction and organic extraction: Genomic extraction was carried out using Master Pure $^{\mathrm{TM}}$ Complete DNA and RNA Purification Kit, following Tissue Samples and Precipitation of Total DNA protocols. The samples were blended in the solvent, stirred for $48 \mathrm{~h}$ and kept at $4^{\circ} \mathrm{C}$ until further used.

Molecular screening: Polymerase Chain Reaction (PCR) amplification and primers were design using Primer Premium 5 software based on region of interest. The reaction mixture volume of $25 \mu \mathrm{L}$ 
contained 1X BST buffer (Biosyntech Inc.), $1.8 \mathrm{mM}$ $\mathrm{MgCl}_{2}, 200 \mu \mathrm{m}$ dNTPs, 20 pmole of reverse primer and forward primer, $1 \mathrm{U}$ taq polymerase. The PCR programs were, initial denaturation at $94^{\circ} \mathrm{C}$ for $5 \mathrm{~min}$, 35 cycles of denaturation at $94^{\circ} \mathrm{C}$ for $5 \mathrm{sec}$, annealing temperature depended on the particular primer for $1 \mathrm{~min}$, extension at $72^{\circ} \mathrm{C}$ for $2 \mathrm{~min}$ and final extension at $72^{\circ} \mathrm{C}$ for $3 \mathrm{~min}$.

Disc diffusion test: Whatman paper No. 1 filter paper was used to make sterile discs in order to screen for the antibacterial activities of $G$. changii and $E$. denticulatum. Filter paper was punctured to the shape of commercial antibiotic disc and discs were autoclaved at $121^{\circ} \mathrm{C}$ for 15 min. The methanol extract of either G. changii or $E$. denticulatum was solubilized in the $60 \%$ methanol. The suspension of bacteria culture was prepared according to the MacFarland standard 0.5 and was lawned onto the Mueiller Hinton agar plate to produce the bacteria field. A sterile of punctured filter papers was placed on the bacteria field by a sterile forceps and the solubilized extract then pipettes out onto the surface of filter paper on the bacteria field. 60\% methanol was used as a negative control while the commercial antibiotic discs were used as a positive and negative control. Finally, the plate was incubated at $37^{\circ} \mathrm{C}$ and the zone of inhibition is observed after 24-48 h.

Minimal Inhibitory Concentration Test (MIC) and Minimal Bactericidal Concentration Test (MBC): Sensitivity of bacteria to either G. changii or E. denticulatum methanol extracts can be measured by using a tube dilution technique, which determines the MIC ad MBC of seaweed used in this study in vitro. These tests were done to determine the lowest concentration of either $G$. changii or E. denticulatum extract, where it can show the bactericidal and bacteriostatic effect. Test was performed in 96-well microtitre plates, so that, several replicates of each sample can be run. All isolates were grown until the concentration is equal to $0.5 \mathrm{MacFarland}$ standard at $37^{\circ} \mathrm{C}$ and diluted in Mueller Hinton Broth (MHB; Difco Laboratories, Detroit, USA) supplemented with $2 \% \mathrm{NaCl}$ (Thornsberry and McDougal, 1983) to a concentration of $50 \mathrm{mg} \mathrm{mL}^{-1}$ for $G$. changii and $40 \mathrm{mg} \mathrm{mL}^{-1}$ for E. denticulatum and serial two-fold dilutions were made.

Table 1: Minimum Inhibitory Concentrations (MIC) of the extracts against gram-positive bacterial growth

\begin{tabular}{lll}
\hline Microorganism & $\begin{array}{l}\text { MIC 70\% MeOH SC3 } \\
\left(\mathrm{mg} \mathrm{mL}^{-1}\right)\end{array}$ & $\begin{array}{l}\mathrm{MIC} \mathrm{70 \%} \mathrm{MeOH} \mathrm{SC5} \\
\left(\mathrm{mg} \mathrm{mL}^{-1}\right)\end{array}$ \\
\hline S. aureus (STR9) & 125 & 125 \\
S. aureus (N8) & 250 & 125 \\
S. pyogens & 125 & 125 \\
\hline
\end{tabular}

Then, the suspension of $S$. aureus culture was added into the 96-well microtitre plates containing diluted sample of either $G$. changii or E. denticulatum extract. Finally, the 96-well microtitre plates containing diluted sample of either $G$. changii or E. denticulatum and bacteria was then incubated overnight at $37^{\circ} \mathrm{C}$ with constant shaking on the shaker. On the next day, the diluted sample of S. aureus-G. changii or S. aureus-E. denticulatum in the 96-well microtitre plates were plated out onto the Mueiller-Hinton agar (Merck, Germany) plate according to the concentration of either $G$. changii or E. denticulatum extract. The plate was incubated at $37^{\circ} \mathrm{C}$ for $24 \mathrm{~h}$ in the incubator. Finally, the number of bacteria colonies developed on each agar plates was counted. MIC for Sea cucumber extracts against bacterial growth were determined using the serial dilution method. $900 \mu \mathrm{L}$ of freshly prepared Mueller Hinton broth was placed in $2 \mathrm{~mL}$ of eppendorf tube (Table 1). An aliquot of $100 \mu \mathrm{L}$ of bacterial suspension at a concentration of $0.5 \mathrm{Mc}$ Farland were pipette into the first tube, followed by $1.0 \mathrm{~mL}$ of the respective extracts and mixtures were re suspended accordingly. Then $1 \mathrm{~mL}$ of mixture were taken out and re suspend in another tube contain the same mixture and repeat 10 times.

\section{RESULTS}

Clear inhibition zones around the antibiotic discs showed the sensitivity to the antibiotic compounds. Seven antibiotic discs were used in each plate including erythromycin $(15 \mu \mathrm{g})$, methicillin $(5 \mu \mathrm{g})$, mupirocin $(5 \mu \mathrm{g})$, gentamycin $(10 \mu \mathrm{g})$, vancomycin $(30 \mu \mathrm{g})$, penicillin $(10 \mu \mathrm{g})$ and oxacillin.

Disc diffusion test: In this test, filter paper disc impregnated with $G$. changii extract showed clear inhibition zone to S. aureus and S. pyogenes (Fig. 1). The clear inhibition zones are seen in both MRSA and nonMRSA isolates. For isolates of E. coli, P. aeruginosa and $K$. pneumoniae (Fig. 2 and 3) there are no inhibition zones around discs impregnated with methanol extract of $G$. changii. The antibiotic disc which was used as positive control vancomycin showed clear inhibition zones around both MRSA and non-MRSA isolates.

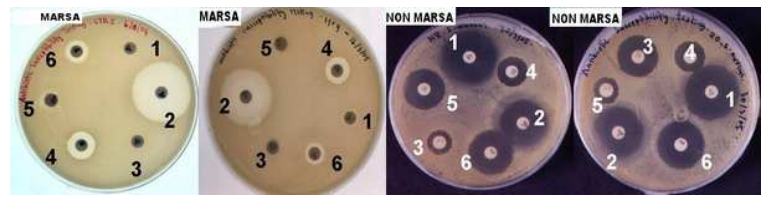

Fig. 1: The disc diffusion assay for determination of MRSA and non-MRSA isolates: (1) methicillin, (2) mupirocin, (3) gentamycin, (4) vancomycin, (5) penicillin, (6) erythromycin 


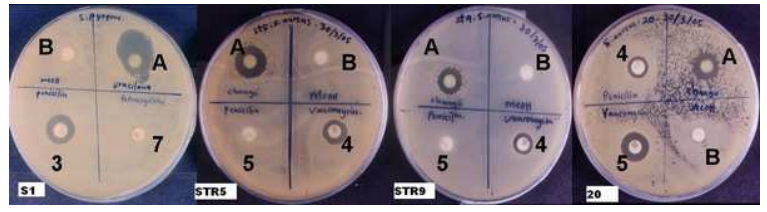

Fig. 2: Disc susceptibility testing of Gracilaria changii on Streptococcus pyogenes (S1), S. aureus (STR5), S. aureus (STR9) and S. aureus (20). Filter paper disc impregnated with extract (A) and (B) $60 \%$ methanol. Antibiotics gentamycin (3), vancomycin (4) penicillin (5) and tetracycline (7) were used as positive control

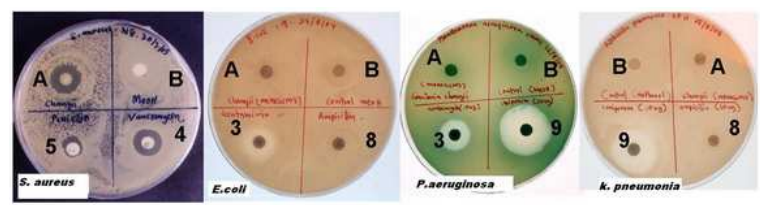

Fig. 3: Disc susceptibility testing of $G$. changii on S.aureus (N8), E. coli, P. aeruginosa and $K$. pneumonia. Filter paper disc impregnated with extract (A) and (B) $60 \%$ methanol. Antibiotics gentamycin (3), vancomycin (4) penicillin (5), ampicillin (8) and Imipenem (9) were used as positive control

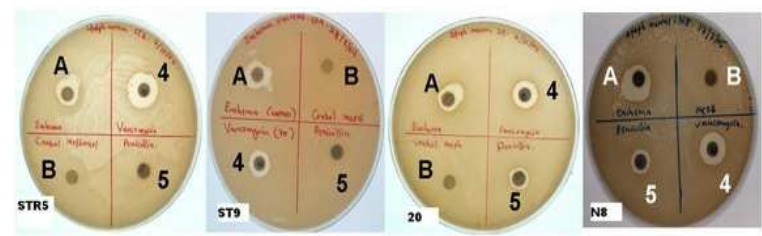

Fig. 4: Disc susceptibility testing of $E$. denticulatum on $S$. aureus (STR5), S. aureus (STR9), S. aureus (20) and $S$. aureus (N8). Filter paper disc impregnated with extract (A) and (B) 60\% methanol. Antibiotics vancomycin (4) and penicillin were used as positive control.

Discs impregnated with methanol extract of E. denticulatum similar clear inhibition zone around discs are seen in the MRSA and lawn of non-MRSA isolates (Fig. 4). Clear inhibition zones are also seen in isolates lawned with $S$. pyogenes. Plates lawned with gram negative bacteria namely E. coli, V. cholerae, $P$. aeruginosa and $K$. pneumoniae (Fig. 5) showed no inhibition zone around discs. The results of inhibition and no inhibition zones represented for tests that were performed twice. The zones of diameter values are as average of two readings.

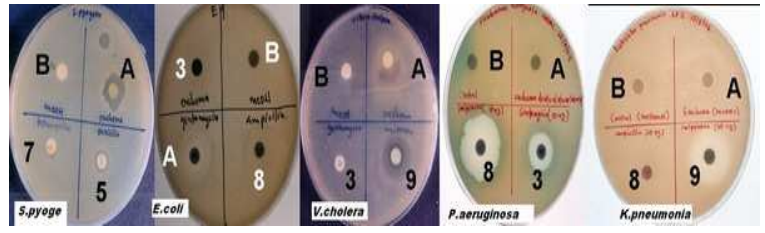

Fig. 5: Disc Susceptibility Testing of E. denticulatum on S. pyogens, E. coli, V. cholera, P. aeruginosa and $K$. pneumonia. Filter paper disc impregnated with extract (A) and (B) $60 \%$ methanol. Antibiotics gentamycin (3), penicillin (5), tetracycline (7) ampicillin (8) and Imipenem (9) were used as positive control

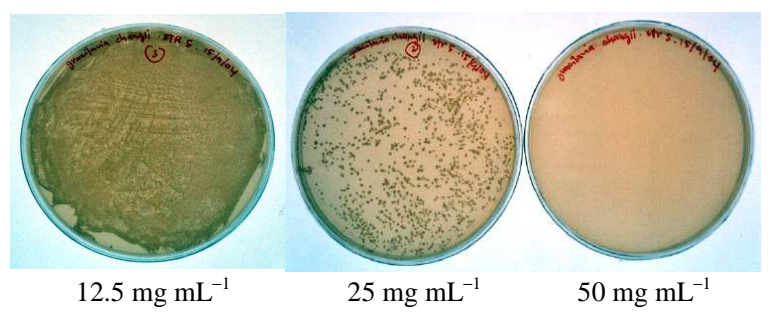

Fig. 6: MIC and MBC test for MRSA isolate with G. changii extract. The reducing of colonial growth of STR5 isolates in different concentrations of $G$. changii methanol extract. MBC-50 mg mL $\mathrm{mL}^{-1}$ MIC-25 mg mL

Table 2: Minimal bactericidal concentration and minimal inhibitory concentration test for $G$. changii extract on MRSA and nonMRSA

\begin{tabular}{llllll}
\hline & & \multicolumn{4}{l}{ Gracilaria changii $\left(\mathrm{mg} \mathrm{mL}^{-1}\right)$} \\
Concentration & Isolate & 50 & 50 & 12.5 & 6.25 \\
\hline No. of colony & STR5 & No colony & $400-500$ & $*$ & $*$ \\
& STR9 & No colony & $300-400$ & $*$ & $*$ \\
& 20 & No colony & 5 & 20 & $*$ \\
& N8 & No colony & 6 & 13 & $*$ \\
\hline
\end{tabular}

Minimal Inhibitory Concentration (MIC) and Minimal Bactericidal Concentration (MBC) determined based on the lowest $G$. changii and E. denticulatum extract concentration reducing colonial growth or killing all bacteria cells. The MIC and MBC tested for $G$. changii and $E$. denticulatum are for two isolates of MRSA and 2 isolates of non-MRSA. Table 2and 3 showed the MIC and MBC of $G$. changii or $E$. denticulatum extract against $S$. aureus while Fig. 6-9 showed the comparison between the numbers of colonies growth in different concentration of either $G$. changii (Fig. 6 and 7) or E. denticulatum (Fig. 8 and 9) extracts. 


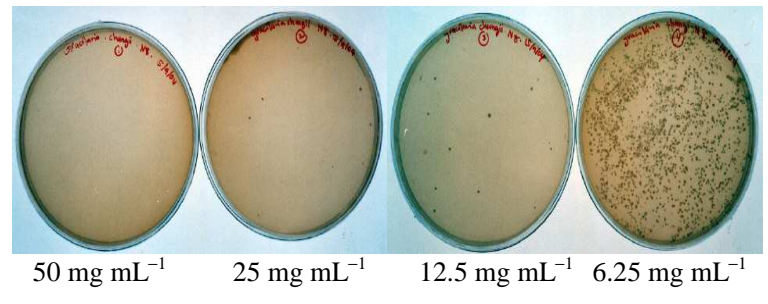

Fig. 7: $M I C$ and MBC test for Non-MRSA isolate with G. changii extract. The reducing of colonial growth of N8 (non-MRSA) isolates in different concentrations of Gracilaria changii methanol extract. MBC-50 mg mL ${ }^{-1}$ MIC-12.5 mg mL

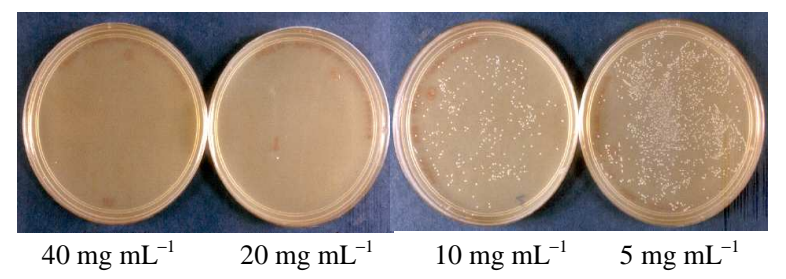

Fig. 8: MIC and MBC test for MRSA isolate with $E$. denticulatum extract. The reducing of colonial growth of STR5 (MRSA) isolates in different concentrations of $E$. denticulatum methanol extract. MBC-40 mg mL ${ }^{-1}$ MIC-20 mg mL ${ }^{-1}$

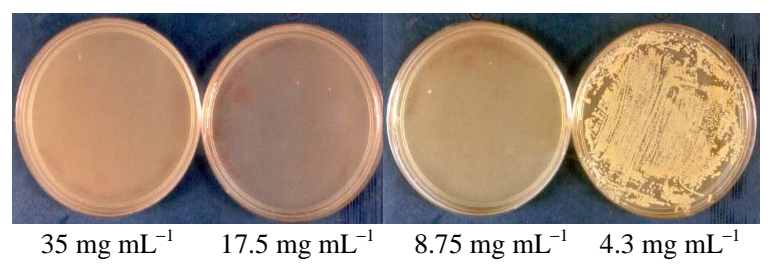

Fig. 9: MIC and MBC test for Non-MRSA isolate with E. denticulatum extract. The reducing of colonial growth of $\mathrm{N} 8$ (non-MRSA) isolates in different concentrations of $E$. denticulatum methanol extract. MBC-17.5 mg mL ${ }^{-1}$ MIC$8.75 \mathrm{mg} \mathrm{mL}^{-1}$

According to the Table 2 and 3, methanol extract of $G$. changii and E. denticulatum showed strong activity irrespective of MRSA and non-MRSA isolates, whereas the MIC and MBC level for $G$. changii extract are 25 and $50 \mathrm{mg} \mathrm{mL}^{-1}$ for MRSA isolates and 12.5 and $50 \mathrm{mg} \mathrm{mL} \mathrm{m}^{-1}$ for non-MRSA isolates, respectively, while the MIC and MBC level for E. denticulatum extract are 20 and $40 \mathrm{mg} \mathrm{mL}^{-1}$ for MRSA isolates and 8.75 and $17.5 \mathrm{mg} \mathrm{mL}^{-1}$ for non-MRSA isolates, respectively.
Table 3: Minimal Bactericidal Concentration and Minimal Inhibitory Concentration Test for E. denticulatum Extract on MRSA and Non-MRSA

\begin{tabular}{|c|c|c|c|c|c|}
\hline \multirow[b]{2}{*}{ Concentration } & \multirow[b]{2}{*}{ Isolate } & \multicolumn{4}{|c|}{ Gracilaria changii $\left(\mathrm{mg} \mathrm{mL}^{-1}\right)$} \\
\hline & & 40 & 20 & 10 & 5 \\
\hline \multirow[t]{5}{*}{ No. of colony } & STR5 & No colony & 1 & $300-400$ & $*$ \\
\hline & STR9 & No colony & 1 & $300-400$ & $*$ \\
\hline & & 35 & 17.5 & 8.75 & 4.38 \\
\hline & 20 & No colony & No colony & 1 & $*$ \\
\hline & N8 & No colony & No colony & 2 & $*$ \\
\hline
\end{tabular}

Note: For the test of $E$. denticulatum extract on non-MRSA isolate, the MIC and MBC level are different due to different starting concentrations of the extract *: Uncountable colonies

\section{DISCUSSION}

Research approaches used in this study was bioassays or preliminary screening which included the screening of antibacterial activity through disc diffusion test and minimal inhibitory concentration tests. A fundamental concept of in vitro susceptibility testing is the measurement of Minimum Inhibitory Concentration (MIC) and Minimal Bactericidal Concentration (MBC) of either $G$. changii or E. denticulatum extract that exhibit their antibacterial activity against Methicillin Resistant S. Aureus (MRSA) and non-Methicillin Resistant S. Aureus (non-MRSA). Both methods were chosen in order to point out if there might be some significant difference between the lowest concentration of both extracts required to inhibit growth of $S$. aureus and the lowest concentration at which both extracts can kill $99.9 \%$ of the initial $S$. aureus inoculums. These were indicated by an absence of visible turbidity of the Mueiller-Hinton broth and an absence of bacterial colonies on the Muieller-Hinton agar. Since the "bactericidal" and "bacteriostatic" terminology originates from either the antibacterial's mechanism is based on inhibiting cell wall formation ("bactericidal") or inhibiting bacterial metabolism or ribosomal protein synthesis ("bacteriostatic") (Zarakolu et al., 1999), the idea is that if cell wall formation is blocked, the organisms will lyse and perish, but if metabolism or protein synthesis is blocked, the organisms merely slow down. While this is true to some degree, bactericidal or bacteriostatic outcomes are dependent on the concentration of the antibacterial agent as well. A low dose of a "bactericidal" antibacterial agent may only inhibit bacterial growth, while a high dose of a "bacteriostatic" antibacterial agent will be bactericidal. Additionally, according to Zarakolu et al. (1999), organisms which are not proliferating may not be significantly affected by anti-cell wall antibiotics, in 
which case anti-ribosomal antibiotics would be more effective. Therefore, in this study, MIC would be taken as the reference point for the study designations "susceptible or resistant", while MBC determinations would be more certain for the prediction of susceptibility in the cases that required bactericidal therapy rather than bacteriostatic theraphy. MBC and MIC tests were done carefully since it is easy affected by the nature of the bacteria used, the inoculums size and the composition of the culture medium, the incubation time and the conditions of incubation, such as temperature, $\mathrm{pH}$ and aeration. In the present study, the reading of MIC and MBC which were based on the number of colonies growing on the Mueiller-Hinton agar is constant for both seaweeds after repeated twice. The methanol extract of $G$. changii reduced the number of colonial growth for MRSA isolates at the extract concentration of $25 \mathrm{mg} \mathrm{mL}$, while in non-MRSA isolates, the reduction in colonial growth can be observed at the extract concentration of $12.5 \mathrm{mg} \mathrm{mL}$. The concentration levels were considered as the MIC level. The cidal effect of $G$. changii extract was indicated by no colonial growth of colonies which was observed when the extract concentration was at $50 \mathrm{mg} \mathrm{mL}^{-1}$ for all $S$. aureus isolates. These concentration levels are considered as the MBC level. The present study also revealed that methanol extract of $E$. denticulatum inhibited or reduced the growth of $S$. aureus isolates better than the inhibitory activity showed by the methanol extract of $G$. changii. Since the inhibitory effect of $E$. denticulatum extract to $S$. aureus isolates is greater if compared to the inhibitory effect of $G$. changii extract to $S$. aureus through the disc diffusion test as discussed above, the experimental concentration level for $E$. denticulatum extract was tested at a lower concentration of $G$. changii extract. In this study, the MIC level of $E$. denticulatum extract, which is indicated by the reduced in number of MRSA colonial growth was at $20 \mathrm{mg} \mathrm{mL}^{-1}$ while for non-MRSA was at $8.75 \mathrm{mg} \mathrm{mL}^{-1}$. The MBC effect of the extract was at $40 \mathrm{mg} \mathrm{mL}^{-1}$ for MRSA isolates and $17.5 \mathrm{mg} \mathrm{mL}^{-1}$ for non-MRSA isolates. Preliminary screening of this study revealed the significant finding of antibacterial activity of $G$. changii and E. denticulatum extracts against $S$. aureus isolates. Several significant findings of the present study were found whereby the methanol extract of $G$. changii and $E$. denticulatum exhibited the inhibitory activity against $S$. aureus and $S$. pyogenes. Inhibitory activities of both extracts were indicated both in MRSA and non-MRSA isolates. In comparison to the $G$. changii extract, the methanol extract of E. denticulatum exhibited more intense activity against
MRSA and non-MRSA isolates. The current study revealed that the extract inhibited a MRSA isolate, STR9 and a non-MRSA isolate, N8, with zones of about 3 and $2 \mathrm{~mm}$ more than the inhibition zones around the vancomycin disc, respectively. The isolate, STR5, was also inhibited by the extract but with a smaller inhibition zone which is $1 \mathrm{~mm}$ less than the zone around the vancomycin disc. The extract can be considered valuable as an alternative in the treatment of MRSA and non-MRSA infection substituting penicillin, since this extract inhibited both MRSA and non-MRSA with inhibition zones of $6 \mathrm{~mm}$ and $1 \mathrm{~mm}$ more than the inhibition zone developed around penicillin disc. In addition, both seaweeds extracts also indicated significant inhibitory activity against $S$. pyogenes isolates. However, further research on $S$. pyogenes isolates, was not performed, since this current study is focused on the inhibitory activity of both extracts against $S$. aureus. Ballantine et al. (1987) and Reichelt and Borowitzka (1984), the higher frequency of activity against gram positive bacteria has been observed in most of the surveys of antimicrobial activities from seaweeds if compared with activity against gram negative bacteria. Thus present study also showed the same inhibitory pattern whereby the antibacterial activity of G. changii and E. denticulatum extracts were only observed in gram positive bacteria and no inhibitory activity against tested gram negative bacteria such as E. coli, $V$. cholerae, $P$. aeruginosa and $K$. pneumoniae were indicated. According to Michael et al. (2000), there is several reasons why certain bacteria may develop resistant to certain antimicrobial agents that may explain the findings of the current study on gram negative bacteria. Although, the methanol extract of $G$. changii and E. denticulatum can be classified into the narrow spectrum antimicrobial agents, which acts on only a single group of organism, both extracts are still quite valuable for the control of microorganisms especially MRSA and non-MRSA that fail to respond to available antibiotics. The incorporation of molecular methods for typing of nosocomial pathogens has assisted in efforts to obtain a more fundamental assessment of strain interrelationship (Cockerill and Smith, 2004; Emori and Gaynes, 1993). Two methods of extraction were utilized, methanol extraction and Phosphate Buffer Saline (PBS). The aim was to find the most suitable and effective extraction method of sea cucumber extract to yield active antibacterial substances. Differences in methods used were in obtaining water soluble or hydrophobic fraction. Antibacterial activity was only found using methanol solvent, whereby inhibition in the growth of gram positive pathogens, $S$. aureus and $S$. pyogenes, were observed. The identity of the active compound in the extract cannot be confirmed in current report. 


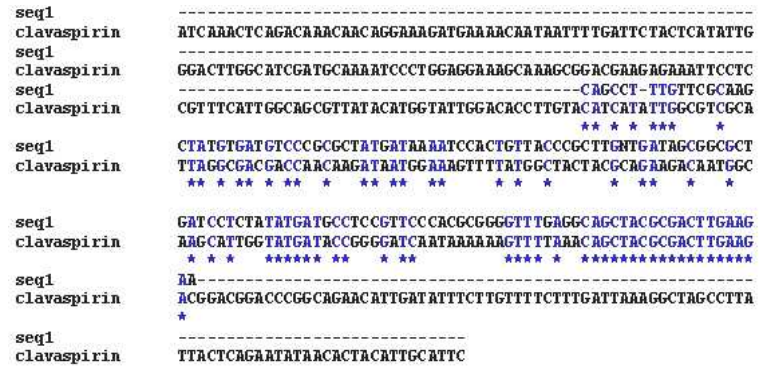

Fig. 10: Alignment between sequencing result of permeabilization gene size 222 bp (seq1) and clavaspirin gene

However, potential antimicrobial agent in tissue of sea cucumber was investigated by molecular screening. The study successfully designed a primer pair for amplifying an antimicrobial peptide gene encoding for membrane permeablization as evidenced from the amplification of the gene at the expected size of 222 bp. Commercialized sequencing further confirmed the identity of the gene after Blast analysis with the published gene in the public domain. The memebrane permeablization gene primers were design from tunicates but could amplify the gene from tissue of sea cucumber 5 as shown in (Fig. 10) alignment between the sequenced product and the permeabilize gene from tunicates showed minor changes in sequenced product due to different species. The finding of antibacterial activity by both extracts against MRSA and non-MRSA strains is hoped to have potential in producing alternative antibacterial agents from natural resources, against resistant $S$. aureus to reduce the infections and fatality.

\section{REFERENCES}

Andersen, J., S. Osbakk, L. Vorland, T. Traavik and T. Gutteberg, 2001. Lactoferrin and cyclic lactoferricin inhibit the entry of human cytomegalovirus into human fibroblasts. Antiviral Res., 51: 141-149. PMID: 11431038

Baker, J.T., 2004. Seaweeds in pharmaceutical studies and applications. Hydrobiology, 116/117: 29-40. DOI: 10.1007/BF00027635

Ballantine, D.L., W.H. Gerwick, S.M. Velez, E. Alexander and P. Guevara, 1987. Antibiotic activity of lipidsoluble extracts from Caribbean marine algae. Hydrobiology, 151-152: 463-469. DOI: 10.1007/BF00046168

Chernysh, S., S.I. Kim, G. Beckeer, V.A. Pleskach and N.A. Filatova et al., 2002. Antiviral and antitumor peptides from insects. Proc. Natl. Acad. Sci. USA., 99: 12628-2632. DOI: 10.1073/pnas.192301899
Chinchar, V.G., J. Wang, G. Murti, C. Carey and L. Rollins-Smith, 2001. Inactivation of frog virus 3 and channel catfish virus by esculentin-2P and ranatuerin-2P, two antimicrobial peptides isolated from frog skin. Virology, 288: 351-357. PMID: 11601906

Cockerill, F.R. and T.F. Smith, 2004. Response of the clinical microbiology laboratory to emerging (new) and reemerging infectious diseases. J. Clin. Microbiol., 42: 2359-2365. PMID: 15184405

De Lucca, E.A.J., 2000. Antifungal peptides: Potential candidates for the treatment of fungal infections. Expert Opin. Investig. Drugs, 9: 273-299. PMID: 11060677

Emori, T.G. and R.P. Gaynes, 1993. An overview of nosocomial infections, including the role of the microbiology laboratory. Clin. Microbiol. Rev., 6: 428-442. PMID: 8269394

Hancock, R.E.W., 2000. Cationic antimicrobial peptides: Towards clinical applications. Expert Opin. Investig. Drugs, 9: 1723-1729. http://journals.tubitak.gov.tr/medical/issues/sag-9929-6/sag-29-6-2-98180.pdf

Liu, Y., J. Luo, C. Xu, F. Ren and C. Peng et al., 2000. Purification, characterization and molecular cloning of the gene of a seed-specific antimicrobial protein from pokeweed. Plant Physiol., 122: 1015-1024. PMID: 10759497

Lowy, F.D., 1998. Staphylococcus aureus infections. Natl. English J. Med., 339: 520-532. PMID: 9709046

Mainous, A.G. and C. Pomeroy, 2001. Management of Antimicrobials in Infectious Diseases: Impact of Antibiotic Resistance. Humana Press, ISBN: 089603-821-1, pp: 349.

Michael, T.M., M.M. John and P. Jack, 2000. Brock Microbiology of Microorganism. 9th Edn., New Jersey, ISBN: 10: 0130662712, pp: 1104.

Reichelt, J.L. and M.A. Borowitzka, 1984. Antimicrobial activity from marine algae: Results of a large scale screening program. Hydrobiology, 116-117: 158-167. DOI: 10.1007/BF00027657

Ridzwan, B.H., M.A. Kaswandi, Y. Azman and M. Fuad, 1995. Screening for antibacterial agents in three species of sea cucumbers from coastal areas of Sabah. Gen. Pharmacol., 26: 1539-43. PMID: 8690242

Schlievert, P.M., 1993. Role of superantigens in human disease. J. Infect. Dis., 167: 997. PMID: 848697

Selitrennikoff, C.P., 2001. Antifungal proteins. Applied Environ. Microbiol., 67: 2883-2894. PMID: 11425698 
Tanaka, K., 2001. P-I3-kinase p85 is a target molecule of proline-rich antimicrobial peptide to suppress proliferation of ras-transformed cells. Jap. J. Cancer Res., 92: 959-967. PMID: 11572764

Thornsberry, C. and L.K. McDougal, 1983. Successful use of broth microdilution in susceptibility tests for methicillin-resistant (heteroresistant) Staphylococci. J. Clin. Microbiol., 18: 1084-1091. PMCID: PMC272846

Washington, W., D.A. Stephen, M.J. William, W.K. Elmey and W.P. Gary et al., 2006. Koneman's Color Atlas and Textbook of Diagnostic Microbiology. 6th Edn., United States, America, ISBN: 13: 978-07817-3014-3.
Welling, M.M., A. Paulusma-Annema, H.S. Balter, E.K. Pauwels and P.H. Nibbering, 2000. Tenehtium-99m labeled antimicrobial peptide discriminate between bacterial infection and sterile inflammations. Eur. J. Nuclear Med., 27: 292-301. DOI: $10.1007 / \mathrm{s} 002590050036$

Zarakolu, P., N. Coplu, A. Arslanturk, B. Levent and E. Guvener, 1999. Comparison of inhibitory and bactericidal activities of cefoperazone + sulbactam against Pseudomonas aeruginosa strains, from 1992-1994. J. Med. Sci., 29: 607-609. http://mistug.tubitak.gov.tr/bdyim/abs.php?dergi=s ag\&rak $=98180$ 